\title{
From old tricks to Netflix: How local are interlingual subtitling norms for streamed television?
}

(iD) Jan Pedersen

Stockholm University

Citation: Pedersen, J. (2018). From old tricks to Netflix: How local are interlingual subtitling norms for streamed television? Journal of Audiovisual Translation, 1(1), 81-100.

Editor(s): A. Jankowska \& J.-L. Kruger

Received: January 22, 2018

Accepted: June 30, 2018

Published: November 15, 2018

Copyright: (C2018 Pedersen. This is an open access article distributed under the terms of the Creative Commons Attribution License. This allows for unrestricted use, distribution, and reproduction in any medium, provided the original author and source are credited.

\section{Abstract}

Like other translation norms, interlingual subtitling norms for television evolve over time, influenced by technology, mediascape development and other trends. Originating in cinema subtitling norms, TV subtitling norms began to develop at national public service broadcasters. Later, norms became international with the rise of the DVD and the proliferation of commercial TV in Europe. These days, the most influential force driving subtitling norms is arguably the global video on demand (VOD) providers. This paper investigates the subtitling guidelines of VOD giant Netflix, in search of the question: How local are interlingual subtitling norms for streamed television? The results show that there is little variation in the initial guidelines, but that they are continually becoming more varied, as they are localized using input from users.

Key words: subtitling, norm development, television, video on demand, Netflix

凶jan.pedersen@su.se; https://orcid.org/0000-0002-9189-0330 


\section{Introduction}

Norms guide most aspects of human behaviour, and translation, in this case in the form of subtitling, is no exception. Subtitling norms for television started to develop early and grew organically as they followed the development of technology and the needs of viewers and subtitlers. There are a few points in time or identifiable events when innovations or dramatic changes to the mediascape have caused subtitling norms to change more dramatically than would otherwise have been the case. One such event was the beginning of the computerised use of the electronic time code, another was the development of the DVD and the boom in commercial television in the 1990s. The most recent such event has been the explosive growth of streamed television content via video on demand (VOD). For each of these events, subtitling norms have become ever more global, guiding the creation of content that is disseminated globally. To summarise, then, in the early days, subtitling norms were national, developed mainly by public service television providers. With the rise of the DVD and the boom in commercial television, they became international, and in the era of streaming, they are becoming global. But just how global are they and to what degree do they still reflect the local?

This paper charts the development of interlingual subtitling norms for television in the past 70 years, and investigates how this development is mirrored in the subtitling norms of today. In order to answer the question of how local current interlingual subtitling norms for streamed television are, this paper presents an analysis of the local language guidelines of the global VOD giant Netflix. The structure of the paper follows that of the norm development, in that it starts by giving insights from public service television, mainly in Scandinavia (section 4.1), zooming out onto the European mediascape (section 4.2), and then finally shifting its focus to the global arena in section 5.

\section{A brief note on norms}

Broadly speaking, translation norms can be either prescriptive or descriptive. Prescriptive norms are based on an authority who decrees or offers advice on how to translate; in other words, such norms prescribe what translation should be like. Descriptive norms describe actual practices, based on observation of translations and translators; in other words, such norms describe what translation is like. Descriptive norms can then be used prescriptively, e.g., by being included in textbooks for students and guidelines for practitioners. Thus, for the learner (and also for the practitioner) it can sometimes be hard to tell the two kinds apart, as descriptive norms also exert regulatory force, be it in textbooks and guidelines or through peer pressure. However, both prescriptive and descriptive norms are organic entities that develop over time (cf. Chesterman, 1997), and this will be described below (in section 4), with a focus on interlingual subtitle norms. 
According to Gideon Toury (1995), translation norms can be found by studying textual sources (i.e. translations) or by studying extratextual sources (such as statements about translations). He warns, however, that extratextual sources are secondary and there may be gaps and even contradictions between textual and extratextual sources (1995). This is so because translators do not always do what they say they do, or what they are told to do. Even so, this paper uses a form of extratextual source by investigating current subtitling norms for streamed television as they appear in subtitling guidelines (section 5).

\section{On AVT choice}

Broadly speaking, European countries have long been considered as dubbing, subtitling or voice-over countries (cf. e.g., Pedersen, forthcoming). This division is based on which way those in power, be they legislators, dictators, cinematographers or distributors, decided to go once the spoken dialogue films, or talkies, arrived in the late 1920s and early 1930s. Before that, when silent movies were all there was (which is an obvious retronym; they were just called movies at the time), audiovisual translation (AVT) was fairly simple. It basically just meant cutting out the source language $(\mathrm{SL})$ intertitles and replacing them with new ones in the target language (TL) (Ivarsson, 2002). In the early days many countries experimented with various modes of AVT before getting set in their ways. Some tried voice-over, some resisted the talkies by removing the sound and inserting intertitles, while others tried dubbing or had translations written into leaflets that the audience could read along. For instance, Swedish cinemas tried dubbing and live voice-over as well as translation leaflets before settling on subtitling (Natzén, forthcoming). Thus, in the early days there was a mix of methods before countries settled (or were ordered to settle; Ivarsson \& Carroll, 1998) on their preferred mode of AVT.

The choice of AVT became more entrenched when television became a serious reality in the early 1950s. After initial experimenting (e.g., with voice-over on Danish television; Gottlieb \& Grigaravičiūtè, 1999), many countries made the same choice for the small screen as they had for the big screen. However, in some countries of Central and Eastern Europe, different modes prevail in different media to this day. For instance, Poland, Bulgaria, Latvia and Lithuania favour voice-over for television and subtitling in cinemas, while Slovakia, the Czech Republic and Hungary mainly use dubbing on television and subtitling in cinemas (Media Consulting Group, 2007).

Apart from small differences based on practical considerations (dubbing and voice-over being the only practical choice for children's content, even in the Scandinavian countries where subtitling is entrenched), there seems to have been stability in the national choice of AVT until the mid-1990s. The introduction of the DVD meant that for home audiences, there was a choice of several dubbed and subtitled versions. Today, when streamed content is gaining ever more market shares, AVT choice can hardly be said to be a monolithic national choice, but rather is the choice of individual 
viewers. These days, viewing habits are many and diverse, and the services offered by online VOD stores, streaming platforms, social media etc. do their best to facilitate this by providing AVT for people to watch whatever they like, whenever they like.

So, AVT has gone from being a national choice to being an individual choice. It is thus not entirely correct to talk about subtitling and dubbing countries any more. However, people are creatures of habit, and they tend to be faithful to the AVT mode to which they are accustomed. This means that we can still use these labels as long as we define subtitling country as shorthand for a country that has historically used subtitling as the main form of AVT for television, even though the choice is no longer national and there is great individual variation. This is therefore how that term is used in this paper, and the same goes for the labels dubbing country and voice-over country. For a further discussion about AVT choice, the reader is referred to Pedersen (forthcoming).

\section{Historical overview of interlingual subtitling norms}

In this section, a historical overview of the development of norms governing the production of interlingual subtitles for television in Europe is presented. The technical development of subtitling will not be presented here, as that has been done elsewhere (cf. e.g., Ivarsson, 2002), the only exception being when technology influences norms. It should be pointed out, however, that the technical norms influence translation norms a great deal because they dictate how much space and choice a subtitler has to work with when translating.

\subsection{The public service era}

In most subtitling countries, the television market was once dominated by public service broadcasters, such as the BBC in the UK, DR in Denmark, YLE in Finland, and so on. These broadcasters employed their own in-house subtitlers, and the norms they followed often developed organically as subtitlers developed their practice. The norms were taught to new people who joined the profession, and after a while these norms were written down in in-house guidelines (e.g., Ivarsson \& Kumlien, 1982). There were some international contacts made when subtitlers met at conferences and discussed aspects of their profession (e.g., Mathiasson, 1984; Nordisk språksekretariat, 1989). Despite this, there was not much international cooperation, and the subtitling norms developed fairly independently in the various broadcasting houses. This comparative isolation accounts for odd differences in national norms, such as the fact that Danish subtitles require a blank space after the so-called speaker dash, whereas Swedish norms, for no apparent reason, do not (Pedersen, 2007). Local traditions and tastes developed, such as the Danes having more and shorter subtitles, to respect cuts in the audiovisual material, whereas Swedes have tended to favour full two-liners, at the cost of disrespecting some (soft) cuts. 
The introduction of personal computers in the 1980s, and particularly the use of electronic timecode that allowed subtitlers to cue subtitles in advance, revolutionised subtitling norms. The fact that subtitlers no longer had to be present to cue subtitles manually when the content was broadcast meant that subtitles could be cued much more precisely. This led to shorter and more precise exposure times, which in turn allowed for higher reading speeds (often expressed in characters per second, or cps). Also, at this time, text became more proportional to letter size rather than identical for all letters, as was the case in the teletext era, which meant that the number of characters per line (cpl) could be increased. In Sweden, for instance, line lengths went from a maximum of 28-32 cpl in the 1980 s to $35-37 \mathrm{cpl}$ in the late 1990s (Pedersen, 2007). The combination of these two factors, i.e. higher reading speeds and longer lines, meant that the need for condensation dropped drastically. There, the condensation rate (i.e. the number of words "lost in translation") dropped from almost half to a third (Pedersen, 2007). These technical innovations were introduced at different times by different broadcasting houses - quite early in Greece and Denmark (Pedersen, 2011) - and it took some time for (conservative) subtitlers to adjust to them. This means that European subtitling norms probably varied the most in the 1980s and early 1990s, while subtitlers adjusted to their new tools.

\subsection{The commercial TV and DVD era}

Many subtitling countries thus entered the 1990s with their own different subtitling norms which were mainly developed at the various public service broadcasters. At this time, however, in many countries, the monopoly of the public service broadcasters was challenged by commercial television stations, which were broadcasting internationally. This led to an unprecedented increase in the number of television channels available to Europeans. Gambier (2003) has shown that the number of television channels increased by a factor of 32 in a space of 13 years (between 1989 and 2002). Many of these new channels, first available via cable or satellite, with some later becoming terrestrial were international, broadcasting the same content in many countries. An example of this is Viasat, which runs several near-identical channels with very similar content in all of the Nordic and Baltic countries. To these multinationals, it makes sense to cooperate with international subtitling companies and to acquire subtitles in all the languages in which they broadcast. Similarly, for distributors of DVDs with many language options, it is also easier and cheaper to outsource their AVT needs, rather than to set up their own translation units or to ask public service broadcasters for assistance. Thus, the development of multinational commercial television companies was accompanied by the growth of international subtitling companies, such as SDI-Media or BTI Studios.

Public service broadcasters normally only produced one subtitled version of televised content in one language, whereas the international subtitling companies produced subtitles in several languages for the same content. In order to maximise this process, these companies started to develop synergies between language versions. The most obvious one was the introduction of master template 
files. These are first-generation translations that are used as templates for second-generation translations, where the subtitlers only have to translate the contents and not spend time on the rather time-consuming segmenting and spotting tasks (for a further description see, for example, Georgakopoulou, 2009). Similarly, the translation of DVDs was often based on so-called Genesis files, pre-spotted subtitle files in the source language (Georgakopoulou, 2009). However, if the international companies were to benefit from these labour-saving processes such as using the same templates, they could not adhere to varying national norms. So, in the 1990s, the commercial companies harmonised the technical norms, but the national subtitling norms were left a great deal weaker for it (Pedersen, 2007). As the public service broadcasters began to outsource (part of) their subtitling, the new international norms started to affect public service subtitling norms as well. An example of how the subtitling norms became more standardised is that Swedish and Danish subtitling norms went from being very different in the 1980 s to becoming so similar that the only significant difference between them at the start of the new millennium was a slightly higher number of subtitles in the Danish versions (Pedersen, 2007). There was some initial reluctance to this norm change, particularly from those downstream in the template flow, so to speak (Pedersen, 2007). However, in the early 2000s, it could be safe to say that, at least when it comes to technical norms such as reading speeds, condensation rates, exposure times and line lengths, most of the European subtitling countries subscribed to the same norms. There are, however, still variations such as in punctuation.

The introduction of the DVD meant that even in traditional dubbing countries such as Spain, Germany, Italy and France, the option to use subtitles became available. This led to subtitles becoming common in these countries even though, presumably, most viewers preferred to watch the dubbed versions. The dubbing countries tended to import the norms that were present in the Genesis files, which meant mainly American intralingual subtitling norms. These norms prescribe a higher pace of subtitles, with more subtitles per minute, higher reading speeds and less condensation. Georgakopoulou (2010) and Sokoli (2009) have shown that there is more omission and reading speeds are lower in Greek DVD subtitles than in Spanish ones, which illustrates this point. In many ways, this is at odds with the best interests of the viewers, as viewers in dubbing countries are less used to reading subtitles, and presumably need more time to do so.

Summing up the historical overview, we find that subtitling norms have gone from being national and mainly developed by public service broadcasters, to becoming international and determined by market forces. Allowing for national variation in minor issues such as punctuation, the main dividing line has gone from national norms to subtitling norms for subtitling versus dubbing (and voice-over) countries. In the case of subtitling countries, norms have evolved via what could be called coerced harmonisation of national norms. In dubbing countries (and voice-over countries, though this seems to be less well researched), norms tend to be based on norms imported from American Genesis files. That was, broadly speaking, the situation in Europe at the dawn of the era of video on demand. 


\section{How local are interlingual subtitling norms in the era of video on demand?}

In this section, we will look at the development of subtitling norms in the era of VOD, by investigating Netflix guidelines. Netflix is possibly the most dominant stakeholder in the VOD world, even though there are other major streaming services such as HBO, Viasat and Amazon Video. In 2016, Netflix had a presence in all countries in the world, except North Korea and Syria (Fetner, Kreeger \& Smith, 2016). Furthermore, the company does not only distribute content, but also produces a great deal of very successful original content, such as House of Cards (Willimon, 2013-), Orange is the New Black (Kohan, 2013-) and The Crown (Morgan, 2016-). Netflix is not only a huge company, but it also takes on various roles when it comes to language localisation. In one way, it can be compared to traditional public service companies in that it provides in-house guidelines. Netflix also uses a recruiting process for freelancers via the Hermes test system (test.hermes.nflex.io), who then work directly for the company. However, it also acts like commercial television stations in that it commissions a great share of its subtitles from independent subtitling companies, such as BTI Studios and SDIMedia (cf. section 4.2). Lastly, it is similar to DVD distributors in that it sometimes buys used subtitle files from other distributors (known as assets; cf. Georgakopoulou, 2010) and commissions English template files, a practice which is synonymous to the use of Genesis files (cf. section 4.2) in the DVD industry. These files are then used for local language versions (Ch. Saka, personal communication, February 2018). Regardless of which path the commissioning takes, all subtitlers are required to use their guidelines, which they call Timed Text Style Guides (TTSGs), whether they work for Netflix directly orfor an intermediary. It can therefore be argued that the Netflix guidelines exert a great deal of pressure on the subtitlers' behaviour and are thus expressions of strong norms. Since Netflix is such an influential stakeholder in the VOD world and since these norms are expressed prescriptively in the TTSGs, an investigation of these may provide a good example of strong subtitling norms in the age of VOD, even though other companies may employ (and enforce) other norms.

The instructions for making the English template file come in a document called English Template Timed Text Style Guide (Netflix, 2018c). This document stipulates norms about line length (42 cpl), duration, reading speed (17 cps for adult programmes and 13 for children's programmes), line treatment, frame gaps, file format, timing, credits, titles, etc. There are then 36 localised language versions (as of February 2018, including English Subtitling for the Deaf and Hard of Hearing, or SDH), and these will be investigated here. To begin with, all the TTSGs also refer to a five-page document called Timed Text Style Guide: General Requirements (Netflix, 2018k). There is a great deal of overlap between the content of this document and the template TTSG, and also some overlap with the local language TTSGs. All TTSGs are available online and provided with a button marked "Provide feedback on this style guide", where subtitlers (and presumably other users) can comment on the content. This feedback is then used to update the TTSGs and is recorded in a change log.

The main focus of this investigation is on the TTSGs. In order to answer the question posed in the title of this paper, all 36 versions were analysed quantitatively, by investigating length, number of subsections, the change log, and whether target language examples are used. Nine TTSGs 
were then analysed qualitatively to determine whether there are any differences that may be due to influence from dubbing, voice-over and subtitling traditions.

\subsection{Quantitative analysis}

In this section, all TTSGs are studied and compared to guidelines from four other subtitling companies. First, printed length in pages will be reported, then the number of subsections, the change logs and last, some findings about target languages.

The TTSGs do not vary very much in length, with one exception. The Japanese TTSG is twice the length of the average TTSG. As it turns out, this is due to it being two guidelines combined - Japanese and Japanese SDH. It is not clear why this should be so. In comparison, there are two separate guidelines for simplified Chinese and traditional Chinese. Apart from the Japanese TTSG, they vary between four and six pages in printed format, with five being the most common. This can be seen in Figure 1 below. 


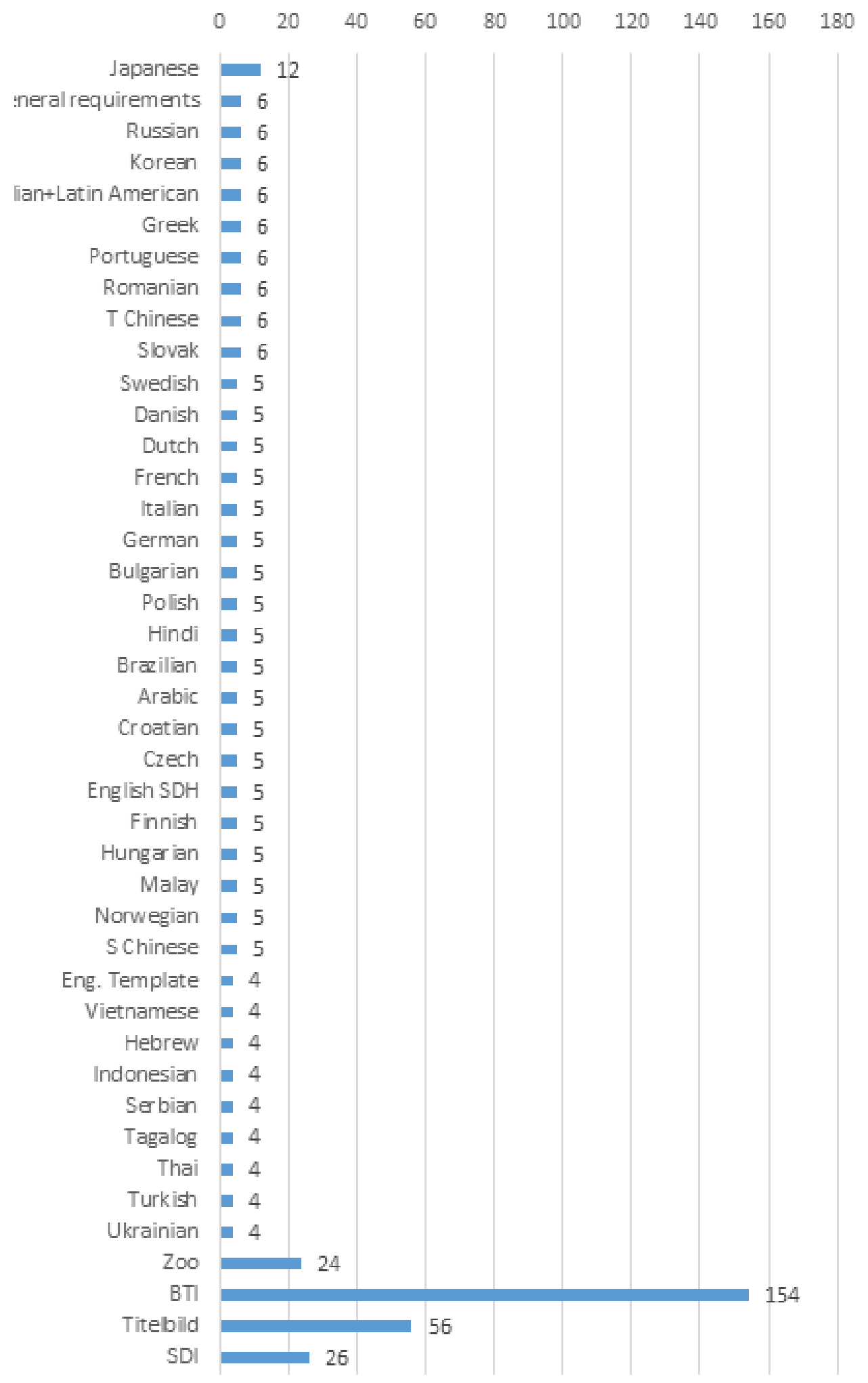

Figure 1. Guideline size in printed pages (excluding change log)

Figure 1 shows the number of printed pages of Netflix TTSGs, excluding the change log, compared to local guidelines of four other commercial companies that operate internationally: ZOO Digital, TITELBILD, SDI-Media and BTI Studios. The comparison may be seen as somewhat unfair, 
as Netflix subtitlers are also supposed to consider the General Requirements document (Netflix, 2018k). However, even if the five pages of that document were to be added to each individual TTSG, they would also still be considerably briefer than those of the other companies, and there would be some overlap in content.

The number of subsections varies between the TTSGs, from 16 (for Indonesian) to 25 (for Japanese), 20 (14 TTSGs) and 21 (11 TTSGs) being the standard number of subsections. It is hardly surprising that there is a correlation between length and number of subsections, even if it is not 1:1. Most subsections are the same for all TTSGs, but some have additional subsections, for unexplained reasons. The content of the TTSG subsections is discussed in section 5.2, Content analysis.

Updates to the TTSG can be tracked through the change log, which lists the number of times a TTSG has been changed over the last two years, and how many changes have been made on each occasion. The average number of times a TTSG had been updated as at 2 February 2018 was 1.3 times, with 10 TTSGs not having been updated in the two years prior (if at all). Figure 2 below shows how many changes (in total) had been made to each TTSG at that point in time: 


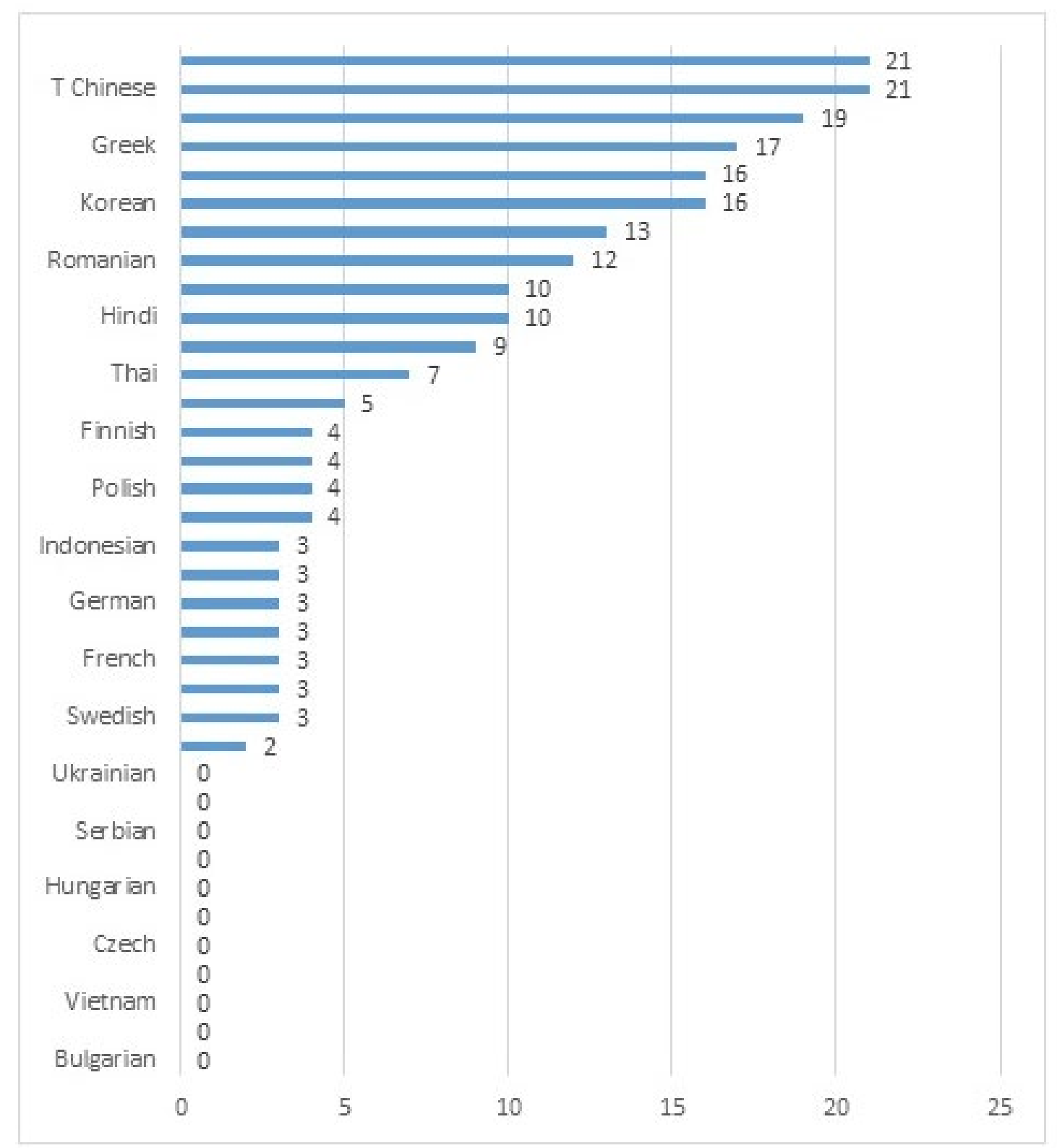

Figure 2. Number of changes to TTSG, according to change log

Figure 2 demonstrates that there is also a correlation between the number of subsections and the number of updates to a TTSG, although not all this correlation does not always hold. The Russian and Traditional Chinese TTSGs have 21 changes but only 20 subsections each, for instance. Conversely, the Japanese TTSG, with 25 subsections, only has two added subsections in the change log. This suggests that TTSGs may have a slightly different number of subsections from the outset or that they had been updated before the records in the change log. It can be presumed that more updates are made in the most common target languages, because there would be more active users providing feedback for those. 
All TTSGs except two (Turkish and Indonesian) are supplied with target language examples. This is the most obvious example of active localisation in the TTSGs. Interestingly, Netflix has mainly divided the world into languages, rather than countries, if one accepts simplified and traditional Chinese as two (written) languages. The French TTSG also makes reference to Canadian French on one occasion. Another example is that Castilian Spanish and Latin American Spanish share the same TTSG. This indicates that the company focuses more on linguistic differences than on national norms. This is particularly interesting since Latin America has a stronger subtitling tradition for commercial TV (D. Orrego-Carmona, personal communication, August 2017) than Spain has, which uses strictly dubbing. The system is not without exceptions, however, as Brazilian Portuguese and European Portuguese each have a TTSG.

\subsection{Content analysis}

In this section, a closer look is taken at the TTSGs of nine languages, in order to determine what Netflix norms actually look like, and whether any consideration has been given to traditions in the choice of AVT. First, three languages with a strong tradition of subtitling have been selected: Swedish, Danish and Dutch. Second, three typical dubbing languages have been selected: German, French and Italian. Last, three languages spoken in countries where there is a strong tradition for voice-over on television have been selected: Russian, Polish and Bulgarian. The rest of this section will compare the content of the various subsections of the TTSGs, focussing on differences that are due to localisation.

The first two subsections are called "Abbreviations" and "Acronyms". Whilst the second subsection on acronyms is identical in all TTSGs (no periods should be used in acronyms), the list of abbreviations varies a great deal between the TTSGs. This is an area where localisation has taken place, and it indicates source vs. target orientation as the list of abbreviations contains forms of address (e.g., Mr. and Mrs.), and indicates whether source or target forms are used. For French, for instance, only TL forms are used, whereas for Swedish there is a mix. However, in traditional Swedish subtitling, only SL forms are normally used (e.g., Broadcast Text Stockholm AB, 2004). Danish lists only TL forms, whereas the practice there is normally also to use SL forms, particularly for English (Lindberg, n.d.). This subsection is inexplicably absent from the Russian TTSG.

The next TTSG subsection contains information about "Character Limitation", i.e. maximum characters per line. It is identical for all (42 cpl), except for Russian, which has $39 \mathrm{cpl}$. This may be due to Russian using the Cyrillic alphabet, but then Bulgarian (and Serbian) also have a 42-character limit.

Curiously, the French TTSG is alone in having a subsection on "Brand Names", which are normally to be generalised (this does not apply to Canadian French). 
"Character Names" are treated very much the same across TTSGs. These should not be translated unless they are meaning-bearing nicknames. Also, official equivalents should be used for historical/mythical characters. The Russian (but not the Bulgarian) TTSG also includes a point about transliteration here.

The subsection on "Continuity" tells the subtitlers not to use dashes or periods to indicate that a sentence continues across more than one subtitle, not even for languages that have this tradition for television, such as Swedish and Danish. The practice of not marking continuity is, however, fairly common in the DVD industry (e.g., Estrup, 2002). The Dutch, interestingly, are told to use three periods to indicate continuity.

The only film or programme genre that gets its own subsection is "Documentary", where subtitlers are told how to present speakers. These instructions are the same across languages, except that the Russian and Polish TTSGs have one less bullet point.

The subsection on "Dual Speakers" instructs on how a dual-speaker subtitle is to be treated. This varies a little as to whether both speakers should be indicated by a speaker dash (not for Russian and Dutch) and whether there should be a blank space after the dash. Swedes and Danes are told not to use a blank space, even though Danes traditionally have used one (Pedersen, 2007).

The subsection on "Font Information" is identical for all: white Arial is to be used.

The rather curiously headed subsection "Forced Narratives" instructs the subtitlers what to do with text on screen. This subsection is rather similar and lengthy (5-6 bullet points) and this could be the source of the Netflix trend that has been the subject of much discussion, namely to elevate subtitles whenever text appears on screen, even if the TTSGs do not expressly say so.

The subsection on "Foreign Dialogue" has three bullet points that say that foreign dialogue should only be translated if meant to be understood, that spelling should be verified, and that foreign words should be italicized if left untranslated.

The next subsection, "Italics", lists when these should be used, and it is very much the same across languages, except for Dutch, where italics are not used to mark speech or other sounds that are distant (e.g., voices on TV, telephones, PA systems). This is a clear case of adherence to local norms (Vercauteren, personal communication, February 2018).

The Russian and Bulgarian TTSGs then have a subsection on "Line Treatment" (maximum of two). Why this is a special subsection, and why it is not included for other languages, which presumably also follow this rule, is unclear. 
The subsection on "Numbers" gives five to eight bullet points that begin fairly similarly. The subsection then may or may not include instructions on weights and measures, time, and decimalisation. It is hard to see a pattern in what type of information is included here, beyond the first few points. This could be an indication that norms are under development and continuously being localised.

The subsection on "Punctuation" is absent from about half the TTSGs investigated here. When it is there, it mainly tells subtitlers when to use blank spaces.

The subsection on "Quotes" is quite lengthy and very similar for most TTSGs, except for the Russian one, where the use of chevrons is included.

The subsection on "Reading Speed" gives the same instructions for all TTSGs: $17 \mathrm{cps}$ for adult programming and $13 \mathrm{cps}$ for children. This seems to be the same for all alphabet-based TTSGs, regardless of language. It is higher than for traditional television norms, and similar to the DVD industry norms.

The subsection on "Repetitions", which is inexplicably absent from the Swedish TTSG, tells subtitlers not to subtitle these.

The subsection on "Songs" includes seven bullet points about the treatment of these. There is some localisation here in that the Italian and German TTSGs prescribe quotation marks for song titles and the Russian and Bulgarian TTSGs lack two points about album and song titles.

"Titles" - this is also a subsection about text on screen, but it only deals with text about main, episode and film titles. The instructions appear to be identical throughout.

The subsection on "Special Instructions" is the most interesting one from a localisation perspective. The subsection starts off with three identical bullet points about not censoring taboo language (albeit not in the Russian TTSG), that dialogue pertinent to the plot should be translated rather than background dialogue, and that errors in the source text should not be replicated. These points are not special in the sense of being language-specific. What then follows is a hold-all of major and minor points that are mainly language-specific. For instance, the German TTSG prescribes using "new German spelling rules" (emphasis removed), and the Italian TTSG has one bullet point with instructions on how to spell "Ok" and another for the spelling of "Beh". The TTSGs (Netflix, 2018a, 2018j) of all three subtitling languages have a bullet point that reads:

In order to better meet the expectations of a Danish [or Swedish or Dutch, depending on TTSG] audience, a condensed translation style is required. Subtitles should be merged as much as possible whenever a character's dialogue extends over several subtitles. Character names should be left out once they have been clearly established. 
This is clearly an attempt at accommodating the tradition of lower reading speeds, common in subtitling countries.

The penultimate subsection is entitled "Speaker ID/Sound Effects for SDH versions" and it contains six bullet points that expressly deal with subtitling for the deaf and hard of hearing. It instructs subtitlers on how to identify speakers and how to reproduce sound effects intersemiotically in subtitles. The Russian and Bulgarian TTSGs contain five extra bullet points that instruct subtitlers to include as much of the original dialogue as possible and to use a reading speed of $20 \mathrm{cps}$ for adult programming and $17 \mathrm{cps}$ for children, plus some other details. The higher reading speed for SDH viewers is possibly problematic compared to that for hearing viewers as "deaf viewers are typically slow readers" (Neves, 2008).

The final subsection directs the subtitlers to various standard "Reference" works on language and style, "for all language-related issues not covered in this document". The Bulgarian TTSG lacks this subsection, but the other TTSGs list one to four such works.

The results of this qualitative analysis are that the "Abbreviations", "Brand Names" (French only) and "Reference" subsections are genuinely localised. There are eight subsections that show varying degrees of localisation: "Special Instructions", "Numbers" "Speaker ID / Sound Effects for SDH versions", "Songs", "Italics", "Continuity", "Punctuation" (where present) and "Dual Speakers". The localisation in the last few is only slight, however. The twelve subsections that remain are identical or near-identical. Thus, when it comes to content, not very much localisation has gone into the TTSGs, at least not when compared to the differences that can be found between subtitling and dubbing countries.

\subsection{Discussion on the localisation of Netflix subtitling norms}

The findings in the previous sections show clearly that Netflix TTSGs are different from those of other companies. Not only are they shorter and less detailed, but they are also structured differently. Other guidelines, like those of Broadcast Text (BTI) or TITELBILD, have clear structures that group the content into domains such as spotting (TITELBILD, 2004) or translation problems (Broadcast Text Stockholm AB, 2004). Netflix TTSGs have a less rigidly organised structure. There is no apparent reason for the inclusion of some subsections, for example why brand names have their own very small subsection in the French TTSG instead of being included in the "Special Instructions" or "Character Names" subsection, or why the "Repetitions" subsection is missing from the Swedish TTSG. It could also be argued that the instructions about cpl and cps would logically be juxtaposed, but they are not, and the same goes for the subsections relating to punctuation. Or indeed why the "Forced Narratives" subsection should be given as much space as the instructions for SDH subtitling, or why SDH is awarded six pages in the Japanese TTSG but only six bullet points 
in other TTSGs. The impression that emerges is that the TTSGs are a work in progress that is continually being developed further via the input from users, as recorded in the change log. This is also where localisation comes in. Whenever a user makes a remark on local practice, and that is accepted into the TTSG, the guidelines become more localised (and presumably more descriptive of local norms). This can be seen particularly in the "Special Instructions" subsection, which is a subsection that often recurs in the various change logs.

One area in which it is particularly fruitful to discuss norm development and variety is reading speeds. Not only is this something that is discussed in guidelines, it is also something that is fairly well researched, both from the perspective of the subtitlers and that of the viewers. Eyetracking research has shown if viewers are to spend less than half of their attention on the subtitles, the reading speed should be at $12 \mathrm{cps}$ (Jensema, 1997; Romero-Fresco, 2015). At a reading speed of $17 \mathrm{cps}$, viewers spend on average more than $80 \%$ of their time reading subtitles (Romero-Fresco, 2015), or start skipping them (Caffrey, 2012; Lång \& Mäkisalo, 2013). In 2016, Szarkowska carried out two large-scale online surveys on subtitle presentation time (i.e. reading speed) and line breaks in interlingual subtitling, aimed at professional subtitlers (2016a) and subtitling companies (2016b). Her results showed that subtitlers reported a great deal of variation, particularly in reading speed, from 9 to $17 \mathrm{cps}$, depending on country and medium (2016a). The pattern is that countries with a long subtitling tradition, such as the Scandinavian countries or the Netherlands, have a lower reported reading speed, whereas others, such as the UK, Poland, France and Brazil, have higher reading speeds (Szarkowska, 2016a). Her surveys verify the difference between Anglophone, dubbing and voice-over countries on the one hand and subtitling countries on the other hand, with the latter being towards the lower end of that span (2016a). This difference is not reflected in the TTSGs. There is, however, an attempt at localisation there, as the special instructions for the "subtitling languages" Swedish, Danish and Dutch instruct subtitlers to condense the content. This is presumably included in order to respect local norms. However, since the reading speed remains the same for all languages, there is very little incentive for subtitlers to actually carry out much condensation, as this is arguably not only "one of the most time-consuming elements of the job" (Szarkowska, 2016a, p. 14) but also a cognitively taxing task.

Norms vary culturally as well as linguistically. An example of cultural differences is that traditionally, the norms for Swedish in Sweden and in Finland (where Swedish is an official language alongside Finnish) differ, for example when it comes to punctuation. This is not at all reflected in the Swedish nor the Finnish TTSG. Linguistically, typology makes it problematic to use the same templates for all languages. The long words of some heavily affixed languages, such as Finnish and Russian (Szarkowska, 2016) call for special attention in line and subtitle breaks. Similarly, German grammar, which requires a verb-final word order in subordinate clauses, means that if there is high subtitle density (which implies many short subtitles rather than fewer long ones), the viewers may have to wait for the next subtitle to appear before they will know what the verb of the clause is. This is not at all reflected in the German TTSG. 
The contents of the Netflix guidelines appear to have developed from a set of prescriptive norms, which are still common to all guidelines. The prescriptive norms are then continually developed via the input from users. Other companies also continually update their guidelines, of course, to reflect norm development and technical development. The difference here is mainly that, particularly for the public service broadcasters, this started as descriptive norms that grew out of inhouse practice. The great similarity among the TTSGs shows that Netflix is basically rebooting subtitling norms, by prescribing the use of the same norms across the board (albeit with local language examples) and then gradually adapting them to local norms via updates. In a way, it could have been useful to have been influenced more by local norms from the outset, as that would have given the viewers in different countries the kinds of subtitles they were used to. Considering the very rapid expansion of VOD in general and of Netflix in particular, it is quite understandable that the company has chosen another approach. When there was suddenly a huge and urgent need for subtitling into many languages, it was probably too time-consuming to research local norms. This must have prompted the use of the one-size-fits-all solution of norms, influenced by DVD norms, which could then be modified as you go along, so to speak.

One question remains, and that is whether the TTSGs are actually representative of practice, as pointed out in section 2. The editors of BTI Studios (Ch. Saka, personal communication, February 2018), who use them for Netflix content, claim that the norms are in fact followed. A brief scan of some Netflix original series in the languages available in Sweden seems to corroborate this. Pending further investigation, the norms expressed in the TTSGs seem indeed to be reflected in the actual subtitles.

\section{Summary and conclusion}

Compared to the development in the 1990s, where the subtitling norms of many countries were homogenised, the development that can be seen for VOD is even less sensitive to local norms. Here, new norms are imposing a one-size-fits-all system, which is then adjusted post hoc. Whereas the early development was that of descriptive norms that then became increasingly prescriptive as the practices that developed in the public service companies were codified in guidelines, the development of Netflix norms seems to be heading in the opposite direction. Initially prescribed norms, set out with the general requirements and in the various language versions, are currently being localised by adding local norms describing local practices. So, instead of descriptive norms developing into prescriptive ones, these are prescriptive norms that are starting to incorporate descriptive norms. The answer to the question "How local are interlingual subtitling norms for streamed television?" will have to be: not very, but they may become so eventually.

It would be interesting to see similar extratextually based studies on other VOD companies, such as HBO or Viasat. Above all, however, we need to find out to what degree the actual texts follow 
the prescriptions of the extratext. In other words, we need to find out to what extent subtitlers working for Netflix (or other VOD companies) do as they are told, and to what extent their subtitles follow other norms.

\section{Biographical note}

Jan Pedersen was educated at the universities of Stockholm, Copenhagen and Uppsala. He received his PhD from Stockholm University in 2007 and was made an Associate Professor in Translation Studies there in 2015. His dissertation is entitled Scandinavian Subtitles, and it is a comparative study of TV subtitling norms in the Scandinavian countries. Jan's research interests include translation studies, translation theory, audiovisual translation, pragmatics and comparative linguistics. He is the former President of the European Association for Studies in Screen Translation (ESIST), member of the European Society for Translation Studies (EST), founding member of the Nordic Network for Translation Studies (TraNor) and co-editor of Journal of Audiovisual Translation and Benjamins Translation Library, and former co-editor of Perspectives - Studies in Translation Theory and Practice. He is a frequent presenter at international conferences and his publications include the 2011 monograph Subtitling Norms for Television, as well as several articles on subtitling, translation and linguistics. He also worked as a television subtitler for many years, subtitling shows like Late Show with David Letterman, the Simpsons and Nikolaj og Julie. Jan is an Associate Professor at Stockholm University, where he holds posts as Deputy Head of the Department of Swedish Language and Multilingualism and as Director of the Institute for Interpretation and Translation Studies, where he also researches and teaches audiovisual translation.

\section{References}

Caffrey, C. (2012). Using an eye-tracking tool to measure the effects of experimental subtitling procedures on viewer perception of subtitles AV content. In E. Perego (Ed.), Eye tracking in audiovisual translation (pp. 223-258). Rome: Aracne.

Chesterman, A. (1997). Memes of translation: The spread of ideas in translation theory. Amsterdam \& Philadelphia: John Benjamins.

Estrup, C. (2002). Quality and anglicisms in DVD subtitling (Unpublished master's dissertation). Copenhagen University: Department of English.

Fetner, C., Kreeger, D., \& Smith, A. (2016, November). Agile Mediascapes. Languages and the Media: Agile Mediacapes - Personalising the future. $11^{\text {th }}$ International Conference on Language Transfer in Audiovisual Media, Berlin.

Gambier, Y. (2003). Introduction: Screen transadaptation: Perception and reception. The Translator, 9(2), 171-189.

Georgakopoulou, P. (2009). Subtitling for the DVD industry. In J. Díaz Cintas \& G. Anderman (Eds.), Audiovisual translation: Language transfer on screen (pp. 21-35). Basingstoke \& New York: Palgrave Macmillan. 
Georgakopoulaou, P. (2010). Reduction levels in subtitling. DVD subtitling: A convergence of trends. Saarbrücken: Lambert Academic.

Gottlieb, H., \& Grigaravičiūtè, I. (1999). Danish voices, Lithuanian voice-over. The mechanics of nonsynchronous translation. Perspectives: Studies in Translatology, 7(1), 41-80.

Ivarsson, J. (2002). Subtitling through the ages: A technical history of subtitles in Europe. Language International, 14(2), 6-10.

Ivarsson, J., \& Carroll, M. (1998). Subtitling. Simrishamn: TransEdit.

Ivarsson, J., \& Kumlien, L. (1982). Handledning för TV-översättare [Guide for TV translators].

Jensema, C. (1997). Viewer reaction to different captioned television speeds. Institute for Disabilities Research and Training. Retrieved from https://www.dcmp.org/caai/nadh30.pdf

Kohan, J. (Creator). (2013-). Orange is the new black [television series]. United States: Netflix.

Lång, J., \& Mäkisalo, J. (2013). Using eye tracking to study the effect of badly synchronized subtitles on the gazer paths of television viewers. New Voices in Translation Studies, 10, 72-86.

Lindberg, I. (n.d.). Nogle regler om TV-tekstning [A few rules about TV subtitling]. Retrieved from http://titlevision.dk/tekstnin.htm

Mathiasson, H. (Ed.) (1984). Rapport från Nordiskt översättarseminarium anordnat i Stockholm 3 - 4 maj 1984. [Report from the Nordic translator's seminar in Stockholm May 3-4 1984].

Media Consulting Group. (2007). Study on dubbing and subtitling needs and practices in the European $\begin{array}{llll}\text { audiovisual industry. Final report. Retrieved } & \text { from }\end{array}$ http://ec.europa.eu/information society/media/overview/ evaluation/studies/index en.htm

Morgan, P. (Creator). (2016-). The crown [Television series]. United States: Netflix.

Natzén, C. (Forthcoming). Film translation in Sweden during the early 1930s. In C. O'Sullivan \& J.F. Cornu (Eds), The translation of films, 1900-1950.

Netflix. (2018a). Danish timed text style guide. Retrieved from https://backlothelp.netflix.com/hc/enus/articles/216014347-Danish-Timed-Text-Style-Guide

Netflix. (2018b). Dutch timed text style guide. Retrieved from https://backlothelp.netflix.com/hc/enus/articles/215350158-Dutch-Timed-Text-Style-Guide

Netflix. (2018c). English template timed text style guide. Retrieved from https://backlothelp.netflix.com/hc/en-us/articles/219375728-English-Template-Timed-

Text-Style-Guide

Netflix. (2018d). French timed text style guide. Retrieved from https://backlothelp.netflix.com/hc/enus/articles/217351577-French-Timed-Text-Style-Guide

Netflix. (2018e). German timed text style guide. Retrieved from https://backlothelp.netflix.com/hc/en-us/articles/217351587-German-Timed-Text-StyleGuide

Netflix. (2018f). Italian timed text style guide. Retrieved from https://backlothelp.netflix.com/hc/enus/articles/215349898-Italian-Timed-Text-Style-Guide

Netflix. (2018g). Norwegian timed text style guide. Retrieved from https://backlothelp.netflix.com/hc/en-us/articles/216015647-Norwegian-Timed-TextStyle-Guide 
Netflix. (2018h). Polish timed text style guide. Retrieved from https://backlothelp.netflix.com/hc/enus/articles/216787928-Polish-Timed-Text-Style-Guide

Netflix. (2018i). Russian timed text style guide. Retrieved from https://backlothelp.netflix.com/hc/en-us/articles/215346638-Russian-Timed-Text-StyleGuide

Netflix. (2018j). Swedish timed text style guide. Retrieved from https://backlothelp.netflix.com/hc/en-us/articles/216014517-Swedish-Timed-Text-StyleGuide

Netflix. (2018k). Timed text style guide: General requirements. Retrieved from https://backlothelp.netflix.com/hc/en-us/articles/215758617-Timed-Text-Style-Guide-

General-Requirements

Neves, J. (2008). 10 fallacies about subtitling for the d/Deaf and the hard of hearing. The Journal of Specialised Translation, 10, 128-143.

Nordisk språksekretariat. (1989). Nordisk TV-teksting: Rapport fra en konferense på Schæffergården ved København 25. - 27. november 1988 [Nordic TV subtitling: Report from a conference at Schæffergården near Copenhagen November 25-27 1988]. Oslo: Nordisk Språksekretariats rapporter 12.

Pedersen, J. (2007). Scandinavian subtitles: A comparative study of subtitling norms in Sweden and Denmark with a focus on extralinguistic cultural references (Unpublished doctoral dissertation). Stockholm University: Stockholm.

Pedersen, J. (2011). Subtitling norms for television: an exploration focusing on extralinguistic cultural references. Amsterdam \& Philadelphia: John Benjamins.

Pedersen, J. (forthcoming). Foreign voices and what to do with them: An interdisciplinary analysis of AVT choice. In A. Baszkowska (Ed.), Proceedings from the first InATra conference.

Romero-Fresco, P. (2015). Final thoughts: viewing speeds in subtitling. In P. Romero-Fresco (Ed.), The reception of subtitling for the deaf and hard of hearing in Europe (pp. 335-343). Bern: Peter Lang.

Sokoli, S. (2009). Subtitling norms in Greece and Spain. In J. Díaz Cintas \& G. Anderman (Eds.), Audiovisual translation: Language transfer on screen (36-48). Basingstoke \& New York: Palgrave Macmillan.

Szarkowska, A. (2016a). Report on the results of an online survey on subtitle presentation times and line breaks in interlingual subtitling - Part 1: Subtitlers. Retrieved from http://avt.ils.uw.edu.pl/files/2016/10/SURE Report Survey1.pdf

Szarkowska, A. (2016b). Report on the results of an online survey on subtitle presentation times and line breaks in interlingual subtitling - Part 2: Companies. Retrieved from http://avt.ils.uw.edu.pl/files/2016/12/Report Survey2 SURE.pdf

Toury, G. (1995). Descriptive translation studies - and beyond. Amsterdam \& Philadelphia: John Benjamins.

Willimon, B. (Creator). (2013-). House of cards [Television series]. United States: Netflix. 